\title{
QUORUM QUENCHING POTENTIALS OF PROBIOTIC ENTEROCOCCUS DURANS LAB38 AGAINST METHICILLIN RESISTANT STAPHYLOCOCCUS AUREUS
}

\author{
SEENIVASAN BOOPATHI ${ }^{1}$, GOPAL SELVAKUMAR ${ }^{2}$, NATESAN SIVAKUMAR ${ }^{1 *}$ \\ ${ }^{1}$ Department of Molecular Microbiology, School of Biotechnology, Madurai Kamaraj University, Madurai - 625 021 , Tamil Nadu, India. \\ ${ }^{2}$ Department of Microbiology, Directorate of Distance Education, Alagappa University, Karaikudi - 630 003, Tamil Nadu, India. \\ E-mail: siva.biotech@mkuniveristy.org
}

Received: 11 January 2017, Revised and Accepted: 23 January 2017

ABSTRACT

Objective: The focus of this study was to explore the nuance strategy to combat the virulence factors of the pathogens by probiotic Enterococcus durans LAB38.

Methods: Probiotic attributes was determined by bile salt tolerance (0.5\%) and Artemia gnotobiotic assay. Quorum sensing (QS) inhibitory activity of the supernatant and ethyl acetate (EA) extract of LAB38 was evaluated using the indicator strains, includes Chromobacterium violaceum CV026 (miniTn5 mutant of ATCC 31532), methicillin-resistant Staphylococcus aureus (MRSA) and Pseudomonas aeruginosa (PA). Reporter strains, Vibrio harveyi BB170 (luxN mutant), BB886 (luxP mutant) and Escherichia coli pSB401 (pACYC184-derived) were used for bioluminescence-based target specificity analysis. Gas chromatography-mass spectrometry (GC-MS) analysis of EA extract was performed using standard protocol.

Results: LAB38 has shown bile salt tolerance and positive probiotic effect toward Artemia salina. In addition, $100 \mu \mathrm{g} / \mathrm{ml}$ EA extract has significantly reduced the violacein production $(37 \pm 1.4 \%)$ in CV026, biofilm formation in MRSA (94 $\pm 0.9 \%)$ and PA $(22 \pm 0.08 \%)$. Further, $200 \mu \mathrm{g} / \mathrm{ml}$ of EA extract has shown inhibition against both autoinducer-1 (AI-1) and AI-2 mediated QS system. Bioluminescence inhibition is directly proportional to the time of exposure. GC-MS result revealed that bromine, sulfur containing molecule and azulene derivative were found in the EA extract.

Conclusion: This is the first report on probiotic E. durans for quorum quenching activity. Hence, the bacterium could be used for future therapeutics application.

Keywords: Autoinducer, Biofilm, Methicillin resistant Staphylococcus aureus, Quorum quenching, Probiotics, CV026.

(C) 2017 The Authors. Published by Innovare Academic Sciences Pvt Ltd. This is an open access article under the CC BY license (http://creativecommons. org/licenses/by/4. 0/) DOI: http://dx.doi.org/10.22159/ajpcr.2017.v10i4.17039

\section{INTRODUCTION}

Biofilm is a matrix of extra polymeric substances often exerted by a bacterial community to protect themselves from external factors such as antibiotics and host defenses, consequently turned as a barrier against killing factors [1]. Notably, $80 \%$ of the bacterial infections are facilitated by biofilm [2]. Biofilm formation is relied on quorum sensing (QS) process, where gene expression is mediated by extracellular signaling molecules called autoinducers (AIs) upon population density [3]. QS process also plays a key role in the expression of virulence factors [4] and antibiotic production [5]

Human gastrointestinal tract is a suitable place for horizontal gene transfer from a diverse group of pathogens, making non-pathogens as virulent ones [6]. Methicillin resistant Staphylococcus aureus (MRSA) emerged as a commonly reported pathogen in the gastrointestinal tract [7]. Astonishingly, $96 \%$ of $S$. aureus causes biofilm-associated infections [8]. However, biofilm-assisted chronic infections of $S$. aureus are difficult to treat due to its fractious nature [9]. Similarly, it has been repeatedly observed that Pseudomonas aeruginosa (PA) colonize in the intestinal tract of the hospitalized and immunosuppressed patients [10]. Besides, PA causes chronic respiratory disease and prolonged chronic rhinosinusitis [11]. Obviously, virulence factors of PA, regulated by QS network are involved in the pathogenesis [12].

Hence, the inhibition of QS became an important target to attenuate pathogenesis, since resistance to antibiotics among pathogens is increasing rapidly and posing a major global threat. Although the pathogens are killed by antimicrobials in a host, their determinants of virulence may persist to harm [13]. Thus, the inhibition of QS network would be a productive alternate way, as it impedes the virulence gene expression without disturbing its growth [14]. Furthermore, it is very interesting to note that QS inhibition enhances the impairment of bacterial biofilm, thereby ease the antibiotic treatment [15].

Ample of reports are found to demonstrate the probiotics potentials of Enterococcus spp. For instance, intestinal tract of mammals is frequently colonized with Enterococcus sp., for the beneficial effects [16]. Probiotics with quorum quenching potential would be a unique dual strategy to control antibiotic-resistant pathogens and to support the host in a positive manner. At the best of our knowledge, there is no report on quorum quenching potential of the probiotic Enterococcus durans. Hence, the aim of this work is (i) to study the probiotic attributes and quorum quenching potential of E. durans LAB38 and (ii) to determine the spectrum of quorum quenching activity.

\section{METHODS}

\section{Bacterial strains and culture condition}

Unpasteurized cow's milk sample was serially diluted in $0.9 \%$ saline and plated on de Man, Rogosa and Sharpe (MRS) agar for $48 \mathrm{hrs}$ at $30^{\circ} \mathrm{C}$. For experimental purposes, the isolate LAB38 was cultured in LuriaBertani (LB) medium with $2 \%$ glucose $(\mathrm{w} / \mathrm{v})$. Indicator organisms such as PA (ATCC 27853) and clinical isolate MRSA were cultured in LB medium. Chromobacterium violaceum CV026 and Escherichia coli pSB401 were maintained in LB medium with respective antibiotics. Vibrio harveyi BB170 and BB886 mutant strains were routinely subcultured in Luria Marine agar, and AI bioassay medium was used for the experimental purpose [17]. Identification of the bacterium was done based on the biochemical and molecular characteristics. Universal 
primers 27F and 1492R were used for 16S rRNA gene amplification. Purified amplicon product was sequenced and analyzed using NCBI nucleotide database, and phylogenetic tree was constructed with highly resembled sequences using MEGA 5.03

\section{Probiotic attributes}

Bile salt tolerance

To confirm the bile salt tolerance, the method described earlier was adopted [18]. Briefly, bacterial pellet was adjusted to 0.1 optical density (OD) using phosphate-buffered saline and it was incubated with or without $0.5 \%$ bile salts for $2 \mathrm{hrs}$. Survival of the bacterium was checked by plating $100 \mu \mathrm{l}$ of inoculum from the respective tubes on MRS agar plate. After $48 \mathrm{hrs}$ of incubation, viable colonies were enumerated.

\section{Artemia gnotobiotic assay}

Artemia salina cysts were cultivated routinely in 3.2\% filtered and autoclaved saline water (FASW). Decapsulation of cysts was performed as described earlier [19]. Decapsulated axenic Artemia was transferred to the tube containing $10 \mathrm{ml}$ of aerated FASW, and then probiotic inoculum (LAB38) was added to reach the final concentration of 0.1 OD. Nannochloropsis sp. was given as a feed at $25 \times 10^{3}$ cells per nauplii. The tubes containing Artemia without bacterial inoculum were used as control. All the tubes were kept under shaking condition for $24 \mathrm{hrs}$ with constant incandescent light. All the experiments were done in axenic conditions and were performed in triplicates.

\section{Quorum quenching assay}

Cell-free supernatant of LAB38 was extracted with half volume of hexane and subsequently with half volume of ethyl acetate (EA) [20]. Extracts were concentrated using Buchi Rotavapor R-210, which were then stored in pre-weighed tubes. Hexane and EA extracts were dissolved in dimethylsulfoxide (DMSO) to make $100 \mathrm{mg} / \mathrm{ml}$ stock solution. Sterile DMSO was used as a control in all experiments to check the solvent effect on QS inhibition.

\section{CV026 plate assay}

Preliminary screening of QS inhibition was determined using C. violaceum CV026 (mini Tn5 mutant of C. violaceum ATCC 31532, $\mathrm{Km}^{\mathrm{r}}$ ) [21]. LB soft agar containing 0.1 OD of CV026 inoculum and $1 \mu \mathrm{g} / \mathrm{ml}$ of C6-HSL (Sigma-Aldrich, USA), was poured over the molten LB hard agar. After solidification, $10 \mu \mathrm{l}$ of filter-sterilized supernatant of the LAB38 was placed and incubated for $48 \mathrm{hrs}$ at $30^{\circ} \mathrm{C}$. LB medium and cinnamaldehyde (Himedia, India) were used as the negative and positive control, respectively.

\section{Pigment quantification assay}

Violacein pigment quantification was performed as described previously [22] with some modification. A volume of $500 \mu$ inoculum consist of CV026 and C-6-HSL $(1 \mu \mathrm{g} / \mathrm{ml})$ was added to each well in a 24-well microtitre plate. Hexane and EA extract were added at a concentration of $100 \mu \mathrm{g} / \mathrm{ml}$. Then, the extract containing inoculum was serially diluted with fresh inoculum by half-dilution technique. After 24 hrs, pigment extraction was done from bacterial pellet using $1 \mathrm{ml}$ of DMSO. After a brief vortex, cell-free pigment extract was measured at $585 \mathrm{~nm}$. CV026 without compound was acts as a control. To confirm the exclusive quorum quenching inhibition (independent from cell growth) of the extract, cell density of CV026 was measured at $600 \mathrm{~nm}$ using ultraviolet visible spectrophotometer (Elico SL-159). The following formula was used to calculate the percentage of inhibition:

$$
\left[\frac{(\text { DMSO control OD }- \text { Compounded treated OD) }}{\text { DMSO control OD }}\right] \times 100
$$

Pyocyanin of Pseudomonas spp. plays a key role in pathogenesis. It was quantified as described elsewhere [23]. Briefly, 0.1 OD adjusted inoculum of PA was incubated for $48 \mathrm{hrs}$ with or without $50 \mu \mathrm{g} / \mathrm{ml}$ of EA extract. Then, the supernatant was extracted with $3 \mathrm{ml}$ of chloroform followed by vortex for few seconds. Chloroform layer was separated and transferred to a new tube along with $1 \mathrm{ml}$ of $0.2 \mathrm{M} \mathrm{HCl}$. After a gentle mixing, all tubes were centrifuged and pink color layer was measured at $520 \mathrm{~nm}$.

\section{Biofilm inhibition assay}

Biofilm inhibition was done by static ring tube assay with filtersterilized supernatant of LAB38. Biofilm inhibition was quantitatively determined (microdilution method) using polystyrene 96-well U bottom plate [24]. Briefly, indicator organisms such as MRSA and PA were adjusted to $0.1 \mathrm{OD}$, respectively, and $200 \mu \mathrm{l}$ of inoculum was added to each well. EA extract of LAB38 was added into the well at a concentration of $100 \mu \mathrm{g} / \mathrm{ml}$. Then, it was subsequently serial diluted for four times to the next well to make half the concentration of the extract. After 36 hrs of static incubation, planktonic cells and nonadhered cells were removed by washing the well with $0.9 \%$ saline thrice. In each well, $0.1 \% \mathrm{w} / \mathrm{v}$ of crystal violet was added and left for 20 minutes. Then, crystal violet was discarded, and the well was washed with de-ionized water to remove excess crystal violet. After 2 minutes of air drying, 33\% acetic acid was used to dissolve crystal violet, and the absorbance was measured at $570 \mathrm{~nm}$ using enzymelinked immunosorbent assay reader (Bio-Rad Model 680). To confirm the quorum quenching effect (independent of cell density) of the EA extract against MRSA and PA, protocol was followed as mentioned in pigment quantification assay, where incubation was kept in shaking condition. Percentage of growth inhibition was calculated as described for violacein inhibition.

\section{Bioluminescence-based target analysis}

Target specificity analysis was performed according to the previously described protocol [25] with little modification. Briefly, $V$. harveyi reporter strains, BB170and BB886 were grown for $18 \mathrm{hrs}$ and diluted in fresh AI bioassay medium in the ratio of 5:100, respectively. Then, $200 \mu \mathrm{g} / \mathrm{ml}$ of EA extract was added and incubated at $28^{\circ} \mathrm{C}$. As far as E. coli pSB401 is concerned, 0.1 OD of inoculum supplemented with 3-oxo-C-6-HSL $(50 \mu \mathrm{g} / \mathrm{ml})$ was used. Luminescence reading was measured at 30 minutes, $1 \mathrm{hr}$ and $3 \mathrm{hrs}$. All the luminescence readings were recorded using Modulus multimode reader (Turner Biosystem) and expressed in relative light units.

\section{Gas chromatography-mass spectrometry (GC-MS) analysis} GC-MS analysis was performed on Thermo GC-Trace Ultra Version 5.0, equipped with DB 5-MS capillary standard non-polar column ( $30 \mathrm{Mts} \times 0.25 \mathrm{~mm}$ ID $\times 0.25 \mu \mathrm{m}$ film). Helium was used as the carrier gas with a flow rate of $1 \mathrm{ml} /$ minute. GC oven temperature was initiated at $70^{\circ} \mathrm{C}$ and increased at a rate of $6^{\circ} \mathrm{C} /$ minute to $260^{\circ} \mathrm{C} .1 \mu \mathrm{l}$ of the EA extract was injected and run for 37.51 minutes in 1:10 split ratio. GCMS peaks were analyzed by the relative abundance of the compounds from each retention time. Peaks were matched with the database of the National Institute of Standard and Technology (http://www.sisweb. com/software/ms/nist.htm).

\section{RESULTS AND DISCUSSION}

This study is an initiative to explore pharmaceutical and commercial importance bacterium, which has exhibited probiotics' attributes and quorum quenching activity. Biochemical and molecular characteristics revealed that the isolate LAB38 belongs to the genera Enterococcus sp. The sequence was submitted to GenBank database and accession no. (KJ720654) was obtained. Phylogenetic analysis revealed that the sequence of LAB38 is highly matched with the sequence of existing probiotic strains. E. durans is a potential probiotic, which additionally produces antimicrobials to defend against pathogens [26]. Although probiotic E. durans has been reported to produce the antimicrobial peptide, this is the first report for quorum quenching activity, isolated from unpasteurized milk. However, many reports are endorsed the concept of quorum quenching activity in probiotics $[27,28]$. 
Probiotic attributes

Tolerance to bile salts is an inevitable credential for probiotics, as bile salts reduce bacterial survival in the intestine by impairing its cell membrane [29]. Viable colony of LAB38 was found about $4.5 \times 10^{3} \mathrm{CFU} / \mathrm{ml}$ in treated and $5.5 \times 10^{3} \mathrm{CFU} / \mathrm{ml}$ in the control media. Although bile salt delayed the growth of LAB38, the bacterium has survived successfully in the bile environment. Evidently, many reports are found to describe the bile salt tolerance of Enterococcus spp. [30]. Artemia is an excellent model organism to study the impact of probiotic bacteria on its survival and development [31]. Artemia has shown $100 \%$ survival in both control and LAB38-treated medium. It clearly indicated that the tested LAB38 has not exhibited any pathogenic effect on Artemia nauplii. In the presence of LAB38, $5.7 \pm 0.5 \% \mu \mathrm{m}$ of length has increased in Artemia than that of control. Moreover, the growth of the Artemia was promoted, in which the development of thoracic segments is clearly observed in the presence of live LAB38 (Fig. 1). Apparently, it delineated that Artemia nauplii acquired probiotic effect from LAB38.

\section{Quorum quenching assay}

\section{Inhibition of QS-regulated pigment production}

Violacein is a purple pigment, which is regulated by QS network. Zone of nonpigmented CV026 was observed as a consequence of the addition of supernatant. Moreover, hexane extract of LAB38 has shown neither antimicrobial nor quorum quenching activity, whereas EA extract has shown inhibitory activity on pigment production without disturbing the growth of CV026. In addition, EA extract $(100 \mu \mathrm{g} / \mathrm{ml})$ has shown a maximum of $37.1 \pm 1.4 \%$ inhibition against violacein pigment production. It was reported that Cuminum cyminum methanol extract $(500 \mu \mathrm{g} / \mathrm{ml})$ has exhibited nearly $30 \%$ inhibition of violacein production [32]. Remarkably, $100 \mu \mathrm{g} / \mathrm{ml}$ of EA extract of LAB38 was sufficient to show $37 \%$ inhibition of violacein production. Moreover, inhibition of pigment production was found even in the one-fourth diluted EA extract containing medium (Fig. 2a). There was a significant negative correlation $\left(r^{2}=0.8738\right)$ between inhibition of violacein production and the concentration of the EA extract. This described that the violacein production is affected in a dosedependent manner.

Pyocyanin is a blue phenazine redox active secondary metabolite of PA causes adverse invasive pulmonary infection by inhibiting the ciliary function, epidermal cell growth and prostacyclin release [33]. In the presence of $50 \mu \mathrm{g} / \mathrm{ml}$ of EA extract, $19.3 \pm 1.2 \%$ of pyocyanin production has inhibited. Thus, the EA extract of the potential probiotic strain has additional value of bearing quorum quenching activity.

\section{Biofilm inhibition}

Biofilm is a prominent virulence factor that eases the colonization and protects the cells from host immune system [34]. Supernatant of LAB38 has shown inhibition against biofilm formation of MRSA and PA. Furthermore, $100 \mu \mathrm{g} / \mathrm{ml}$ of EA extract has exhibited $94 \pm 0.9 \%$ and $22 \pm 0.08 \%$ of inhibition against biofilm formation of MRSA and PA, respectively. Even one-fourth concentration of $100 \mu \mathrm{g} / \mathrm{ml}$ of EA extract has shown inhibition against biofilm of MRSA (Fig. 2b). Significant negative correlation $\left(\mathrm{r}^{2}=0.9158\right)$ between biofilm inhibition and concentration of the EA extract was observed. As the biofilm of PA received moderate inhibition, further dilutions were not made to check the biofilm inhibitory concentration. The ratio of biofilm formation and plantonic cells (OD570/600) clearly indicates that biofilm density of MRSA was significantly reduced $(\mathrm{p}<0.0001)$ in EA extract treated sample $(0.318 \pm 0.007)$, compared to DMSO control $(5.379 \pm 0.149)$. Moreover, cell density was unaffected by the extract, whereas adherence was significantly reduced. Many studies reported that intestinally colonized MRSA spread to the skin surfaces to facilitate the transmission vigorously [35]. Colonization of $S$. aureus in the intestinal tract can be eliminated by probiotic lactic acid bacteria, which eventually kill by its antimicrobial substances [36]. Thus, it is proved that probiotic LAB38 has devastated the biofilm formation of MRSA and PA.

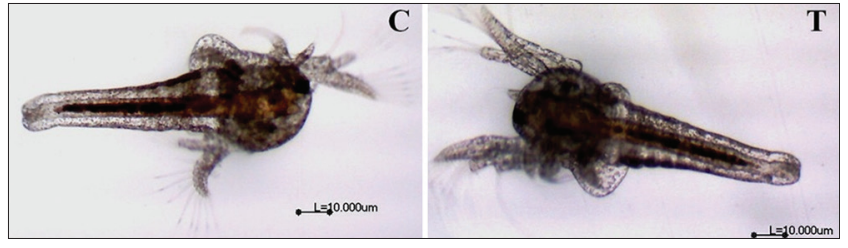

Fig. 1: Artemia gnotobiotic assay. After $24 \mathrm{hrs}$ of incubation, LAB38 treated Artemia (T) has promoted to the next stage of growth than that of control (C)

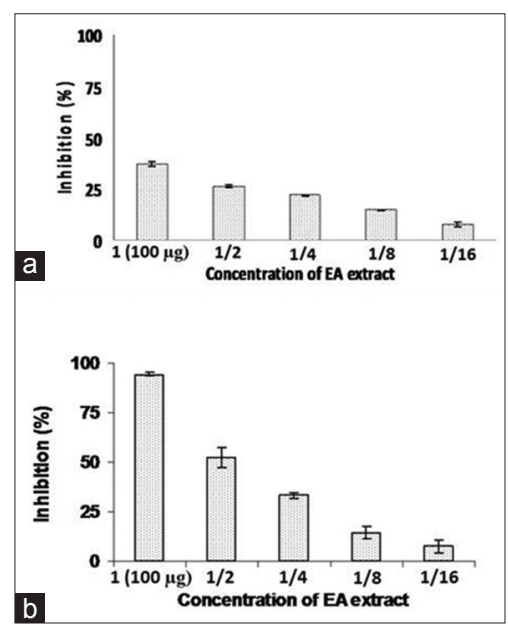

Fig. 2: (a) Inhibition of violacein pigment production by ethyl acetate (EA) extract of LAB38 $(n=3)$. Pigment was estimated spectrophotometrically at $585 \mathrm{~nm}$. Bar 1 represents the inhibition of violacein production by full strength $(100 \mu \mathrm{g} / \mathrm{mL})$ of EA extract. Subsequent bars represent the inhibition of pigment production by half strength of the proceeding concentration. (b) Inhibition of methicillin resistant Staphylococcus aureus (MRSA) biofilm by EA extract of LAB38 $(n=3)$. Bar 1 indicates the inhibition of MRSA biofilm by full strength $(100 \mu \mathrm{g} / \mathrm{ml})$ of LAB38 EA extract. Adjacent bars represent the inhibition of MRSA biofilm by half strength of the proceeding concentration of EA extract

\section{Bioluminescence-based target analysis}

Bioluminescence of $V$. harveyi is regulated by AI-1 and AI-2 type of signaling molecules [25]. V. harveyi $\mathrm{BB} 170$ can respond only to $\mathrm{AI}-2$ type of signaling molecule, as it is sensor $1^{-}$sensor $2^{+}$, whereas BB886 is sensor $1^{+}$sensor $2^{-}$, so it can respond to AI- 1 type of signaling molecules [37]. In this study, $200 \mu \mathrm{g} / \mathrm{ml}$ of EA extract has started to show $14.8 \pm 4.8 \%$ of bioluminescence inhibition in BB170 after $1 \mathrm{hr}$ incubation. Increased trend of bioluminescence inhibition $(53.7 \pm 0.3 \%)$ has exhibited after 3 hrs of incubation (Fig. 3a). Similarly, the same trend of inhibition was found in BB886. After 3 hrs of incubation, $60 \pm 1.8 \%$ of bioluminescence inhibition was observed in $V$. harveyi BB886 in the presence of $200 \mu \mathrm{g} / \mathrm{ml}$ of EA extract (Fig. 3b). There was no reduction in bioluminescence at 30 minutes in both BB170 and BB886. There was a significant positive correlation $\left(\mathrm{r}^{2}=0.8676\right)$ between bioluminescence inhibition and increasing incubation time in BB170. Similarly, a significant correlation $\left(r^{2}=0.7902\right)$ was found in the reporter BB886 as well. Based on the results obtained from these two reporters in response to time of incubation, it is revealed that the inhibition of both QS systems (AI-1 and AI-2) is directly proportional to the time of exposure. In support of this results, it was reported that $\mathrm{AI}-2$ is involved in the biofilm formation and virulent gene expression of Staphylococci [38].

E. coli pSB401 (pACYC184-derived, Tet ${ }^{\mathrm{r}}$ ) is an AHL based biosensor, which can produce bioluminescence in the presence of 3-oxo- 


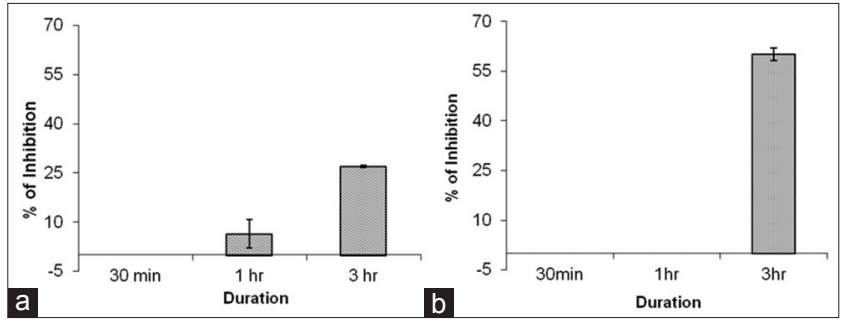

Fig. 3: ( $a$ and b) Represent the effect of ethyl acetate (EA) extract on inhibition of bioluminescence against Vibrio harveyi BB170 and $V$. harveyi BB886, respectively. Bioluminescence-based target analysis was evaluated at different incubation time with $200 \mu \mathrm{g} / \mathrm{ml}$ of EA extract of LAB38 $(\mathrm{n}=3)$

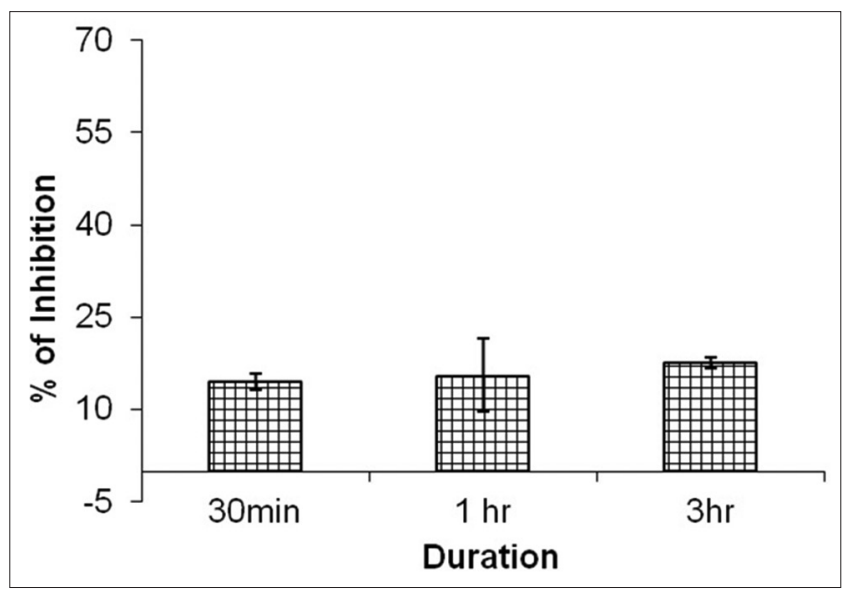

Fig. 4: Bioluminescence inhibition by ethyl acetate extract $(n=3)$ against luxR based reporter strain pSB401
C6-HSL [39]. There was no significant bioluminescence inhibition found in the reporter strain pSB401 (only around 10\% of inhibition was found at all incubation time intervals). Furthermore, there was no significant $\left(r^{2}=0.1692\right)$ correlation between inhibition of bioluminescence and increasing time intervals (Fig. 4). It implied that the extract has not interfered in luxR sensor-based bioluminescence. Obviously, the result delineated that EA extract is unable to quench 3-oxo-C6-HSL signaling molecule or interferes with the receptors of this molecule. In conclusion, from the present work, the EA extract of LAB38 has not exhibited antimicrobial activity against any of the tested strains, which apparently expounded that the inhibition merely was on QS network. Perhaps, EA extract was involved in either the process of inactivating signaling molecules/receptor proteins or competing for the receptor proteins. However, further studies are required to confirm the speculation.

\section{GC-MS analysis}

GC-MS chromatogram revealed about 30 types of different compounds in EA extract. Indeed, five compounds has existed with high percentage of probability, in which four compounds occupied almost $50 \%$ of the total extract. Furthermore, those four peaks at the retention time $11.87,14.13,19.69$, and 12.86 were not matched with the commercial database, revealing the novelty of the compounds (Table 1). Based on the relative abundance, it was speculated that 7,9-di-tert-butyl1-oxaspiro $(4,5)$ deca-6,9-diene-2,8-dione is possibly involved in QS inhibition activity. This compound was an azulene derivative. Moreover, it has not matched with the existing compound databases, which designated the compound as novel. However, some of the metabolites of the extract have been previously reported for biofilm inhibition. Bromine-containing furanones are potential inhibitors of biofilm of several pathogens [40]. Sulfur atom plays a role in biofilm inhibition [41]. Though many QS inhibitors were ascertained from various biological resources [42-44] this study highlighted the significance of the bacterial source especially E. durans and its possible quorum quenching mechanisms.

Table 1: GC MS analysis of ethyl acetate extract

\begin{tabular}{|c|c|c|c|}
\hline $\begin{array}{l}\text { Retention } \\
\text { time }\end{array}$ & Compound name & $\mathbf{p}$ & $\begin{array}{l}\text { Relative } \\
\text { abundance }\end{array}$ \\
\hline 7.2 & Acetic acid, 2-propenyl ester (CAS) & 21.99 & 0.54 \\
\hline 7.83 & 1-butanol (CAS) & 12.67 & 0.75 \\
\hline 10.16 & Isobutyric acid-2-d1 & 41.00 & 6.62 \\
\hline 12.08 & l-alanine, N-propoxycarbonyl-, dodecyl ester & 54.26 & 0.34 \\
\hline 17.65 & E-15-heptadecenal & 9.69 & 0.48 \\
\hline 18.7 & Tetradecanoic acid (CAS) & 84.65 & 2.97 \\
\hline 19.72 & (E)-2-(2H (1)-4-methoxyphenylethene & 18.01 & 1.32 \\
\hline 21.76 & 1-octadecene (CAS) & 8.54 & 2.75 \\
\hline 22.93 & Hexadecanoic acid & 78.74 & 5.82 \\
\hline 23.09 & 2-(dimethylhydrazono) butanal & 63.86 & 2.27 \\
\hline 23.84 & 7,9-di-tert-butyl-1-oxaspiro $(4,5)$ deca-6,9-diene-2,8-dione & 92.34 & 0.97 \\
\hline 24.98 & 2,6-dibromo-3-pyridinyl 3-methyl-2-butenyl ether & 16.64 & 11.87 \\
\hline 25.55 & 1-docosanol, methyl ether & 5.58 & 3.42 \\
\hline 26.85 & (erythro)-5-methyl-2-phenylsulphonylhexan-3-ol & 36.65 & 14.13 \\
\hline 27.40 & 1-methyl-3-(methylamino)-4-pyrazolecarboxamide & 20.85 & 0.92 \\
\hline 28.34 & 2-(n-butylidene)6-n-butylcyclohexanone & 28.98 & 1.76 \\
\hline 28.94 & 5-(N-methylanilino)-4-(N-methyl-N-phenylcarbamoyl)-2,3-dioxo-2,3-dihydrofuran & 62.29 & 1.90 \\
\hline 30.26 & Cyclohexane, 1,3,5-trimethyl-2-octadecyl (CAS) & 53.09 & 0.89 \\
\hline 31.38 & n-tetracosanol-1 & 7.92 & 1.38 \\
\hline 32.46 & 2-benzyl-3,6-dioxo-5-isopropylpiperazine & 94.02 & 0.44 \\
\hline 32.71 & 2-nonadecanone & 9.07 & 0.31 \\
\hline 33.14 & Di-(2-ethylhexyl) phthalate & 21.28 & 1.31 \\
\hline 33.79 & Cyclo-(l-leucyl-l-phenylalanyl) & 82.27 & 0.37 \\
\hline 34.42 & Octacosyl trifluoroacetate & 3.92 & 0.78 \\
\hline 34.75 & 4-(3-hydroxypropynyl)-3-(2-nitroethyl)indole & 69.08 & 1.83 \\
\hline 35.52 & 1-acetyl-4-methyl-1,3-dihydropyrrole-2,2-dicarboxylic acid, diethyl ester & 7.13 & 12.86 \\
\hline 36.23 & Diethyl 2-methylphenyl(methylthio)methanephosphonate & 46.11 & 0.29 \\
\hline 39.11 & Hexatriacontyl pentafluoropropionate & 3.14 & 0.58 \\
\hline Total & & & 100.1 \\
\hline
\end{tabular}

GC-MS: Gas chromatography-mass spectrometry, P: Probability 


\section{CONCLUSION}

In this comprehensive study, the probiotic E. durans showed immense potential to curb the pathogenesis in terms of quorum quenching. Indeed, it has the potential to inhibit the biofilm of MRSA and PA. The results implied that the extract has the inhibitory activity against both AI-1 and AI-2 mediated QS systems. Furthermore, a broad range of QS inhibition was explored with clear evidence using reporter strains such as $C$. violaceum CV026, E. coli pSB401, V. harveyi BB170 and BB886. It was speculated that the key azulene derivative might be involved in the quorum quenching mechanism, as the molecule was relatively abundant in the extract, but confirmation and its mechanisms of activity remain to be elucidated. Our results suggested that LAB38 has commercial value, as it has both probiotic and quorum quenching attributes.

\section{ACKNOWLEDGMENTS}

The authors thank University Grant Commission, New Delhi, for their financial support (Project No.: 41-1171/2012, date 07-07-2012). We thank Prof. S. Kjelleberg (UNSW, Australia) for the generous donation of C. violaceum CV026. We are very grateful to Dr. Sathish Rajamani for his valuable gift of bioluminescent mutant strains. We are very thankful to Prof. S. Karuthapandian (Alagappa University, India) for Luminometer facility. We thank Dr. S. Gopinath, Post Doctoral Fellow, for assisting manuscript preparation. We thank DST-PURSE for instrumentation facility.

\section{REFERENCES}

1. Gupta P, Sarkar S, Das B, Bhattacharjee S, Tribedi P. Biofilm, pathogenesis and prevention - A journey to break the wall: A review. Arch Microbiol 2016;198(1):1-15.

2. Joseph R, Naugolny A, Feldman M, Herzog IM, Fridman M, Cohen Y. Cationic pillararenes potently inhibit biofilm formation without affecting bacterial growth and viability. J Am Chem Soc 2016;138(3):754-7.

3. Fazli M, Almblad H, Rybtke ML, Givskov M, Eberl L, Tolker-Nielsen T. Regulation of biofilm formation in Pseudomonas and Burkholderia species. Environ Microbiol 2014;16(7):1961-81.

4. Zhu J, Miller MB, Vance RE, Dziejman M, Bassler BL, Mekalanos JJ. Quorum-sensing regulators control virulence gene expression in Vibrio cholerae. Proc Natl Acad Sci U S A 2002;99(5):3129-34.

5. Liu X, Bimerew M, Ma Y, Müller H, Ovadis M, Eberl L, et al. Quorum-sensing signaling is required for production of the antibiotic pyrrolnitrin in a rhizospheric biocontrol strain of Serratia plymuthica. FEMS Microbiol Lett 2007;270(2):299-305.

6. Huddleston JR. Horizontal gene transfer in the human gastrointestinal tract: Potential spread of antibiotic resistance genes. Infect Drug Resist 2014; 7:167-76.

7. Boyce JM, Havill NL, Maria B. Frequency and possible infection control implications of gastrointestinal colonization with methicillinresistant Staphylococcus aureus. J Clin Microbiol 2005;43(12):5992-5.

8. Szczuka E, Urbanska K, Pietryka M, Kaznowski A. Biofilm density and detection of biofilm-producing genes in methicillinresistant Staphylococcus aureus strains. Folia Microbiol (Praha) 2013;58(1):47-52.

9. Gil C, Solano C, Burgui S, Latasa C, García B, Toledo-Arana A, et al. Biofilm matrix exoproteins induce a protective immune response against Staphylococcus aureus. Biofilm infection. Infect Immun 2014;82:1017-29.

10. Markou P, Apidianakis Y. Pathogenesis of intestinal Pseudomonas aeruginosa infection in patients with cancer. Front Cell Infect Microbiol 2014; 3(115):247-64.

11. Nomura K, Obata K, Keira T, Miyata R, Hirakawa S, Takano K, et al. Pseudomonas aeruginosa elastase causes transient disruption of tight junctions and down regulation of PAR-2 in human nasal epithelial cells. Respir Res 2014;15:21.

12. Christiaen SE, Matthijs N, Zhang XH, Nelis HJ, Bossier P, Coenye T. Bacteria that inhibit quorum sensing decrease biofilm formation and virulence in Pseudomonas aeruginosa PAO1. Pathog Dis 2014;70(3):271-9.

13. Tubby S, Wilson M, Nair SP. Inactivation of staphylococcal virulence factors using a light-activated antimicrobial agent. BMC Microbiol 2009;9:211

14. Vattem DA, Mihalik K, Crixell SH, McLean RJ. Dietary phytochemicals as quorum sensing inhibitors. Fitoterapia 2007;78(4):302-10.
15. Brackman G, Cos P, Maes L, Nelis HJ, Coenye T. Quorum sensing inhibitors increase the susceptibility of bacterial biofilms to antibiotics in vitro and in vivo. Antimicrob Agents Chemother 2011;55(6):2655-61.

16. Roy SD, Gao P, Garsin DA, Harvey BR, Kos V, Nes IF, et al. Transcriptional and post transcriptional control of enterococcal gene regulation. In: Gilmore MS, Clewell DB, Ike Y, Shankar N, editors. Enterococci: From Commensals to Leading Causes of Drug Resistant Infection. Boston: Massachusetts Eye and Ear Infirmary; 2014.

17. Miyamoto CM, Meighen EA. Involvement of LuxR, a quorum sensing regulator in Vibrio harveyi, in the promotion of metabolic genes: ArgA, purM, lysE and rluA. Biochim Biophys Acta 2006;1759(6):296-307.

18. Argyri AA, Zoumpopoulou G, Karatzas KA, Tsakalidou E, Nychas GJ, Panagou EZ, et al. Selection of potential probiotic lactic acid bacteria from fermented olives by in vitro tests. Food Microbiol 2013;33(2):282-91.

19. Sorgeloos P, Lavens P, Léger PH, Tackaert W, Versichele D. Manual for the Culture and Use of the Brine Shrimp Artemia in Aquaculture. Ghent: Artemia Reference Center; 1986. p. 319.

20. Katerere DR, Eloff JN. Antibacterial and antioxidant activity of Sutherlandia frutescens (Fabaceae), a reputed anti-HIV/AIDS phytomedicine. Phytother Res 2005;19(9):779-81.

21. McClean KH, Winson MK, Fish L, Taylor A, Chhabra SR, Camara M, et al. Quorum sensing and Chromobacterium violaceum: Exploitation of violacein production and inhibition for the detection of N-acylhomoserine lactones. Microbiology 1997;143:3703-11.

22. Choo JH, Rukayadi Y, Hwang JK. Inhibition of bacterial quorum sensing by vanilla extract. Lett Appl Microbiol 2006;42(6):637-41.

23. Essar DW, Eberly L, Hadero A, Crawford IP. Identification and characterization of genes for a second anthranilate synthase in Pseudomonas aeruginosa: Interchangeability of the two anthranilate synthases and evolutionary implications. J Bacteriol 1990;172(2):884-900.

24. Jiang P, Li J, Han F, Duan G, Lu X, Gu Y, et al. Antibiofilm activity of an exopolysaccharide from marine bacterium Vibrio sp. QY101. PLoS One 2011;6(4):e18514.

25. Bassler BL, Greenberg EP, Stevens AM. Cross-species induction of luminescence in the quorum-sensing bacterium Vibrio harveyi. J Bacteriol 1997;179(12):4043-5.

26. Hanchi H, Hammami R, Kourda R, Hamida JB, Fliss I. Bacteriocinogenic properties and in vitro probiotic potential of Enterococci from Tunisian dairy products. Arch Microbiol 2014;196(5):331-44.

27. Nhan DT, Cam DT, Wille M, Defoirdt T, Bossier P, Sorgeloos P. Quorum quenching bacteria protect Macrobrachium rosenbergii larvae from Vibrio harveyi infection. J Appl Microbiol 2010;109(3):1007-16.

28. Yun B, Oh S, Griffiths MW. Lactobacillus acidophilus modulates the virulence of Clostridium difficile. J Dairy Sci 2014;97(8):4745-58.

29. Jin LZ, Ho YW, Abdullah N, Jalaludin S. Acid and bile tolerance of Lactobacillus isolated from chicken intestine. Lett Appl Microbiol 1998;27(3):183-5.

30. Jahan M, Krause DO, Holley RA. Antimicrobial resistance of Enterococcus species from meat and fermented meat products isolated by a PCR-based rapid screening method. Int $\mathrm{J}$ Food Microbiol 2013;163(2-3):89-95.

31. Marques A, François JM, Dhont J, Bossiera P, Sorgeloosa P. Influence of yeast quality on performance of gnotobiotically grown Artemia. J Exp Marine Biol Ecol 2004;310:247-64.

32. Musthafa KS, Ravi AV, Annapoorani A, Packiavathy IS, Pandian SK. Evaluation of anti-quorum-sensing activity of edible plants and fruits through inhibition of the N-acyl-homoserine lactone system in Chromobacterium violaceum and Pseudomonas aeruginosa. Chemotherapy 2010;56(4):333-9.

33. Chai W, Zhang J, Duan Y, Pan D, Liu W, Li Y, et al. Pseudomonas pyocyanin stimulates IL-8 expression through MAPK and NF-kB pathways in differentiated U937 cells. BMC Microbiol 2014;14:26.

34. Begun J, Gaiani JM, Rohde H, Mack D, Calderwood SB, Ausubel FM, et al. Staphylococcal biofilm exopolysaccharide protects against Caenorhabditis elegans immune defenses. PLoS Pathog 2007;3(4):e57.

35. Bhalla A, Aron DC, Donskey CJ. Staphylococcus aureus intestinal colonization is associated with increased frequency of $S$. aureus on skin of hospitalized patients. BMC Infect Dis 2007;7:105.

36. Vesterlund S, Karp M, Salminen S, Ouwehand AC. Staphylococcus aureus adheres to human intestinal mucus but can be displaced by certain lactic acid bacteria. Microbiology 2006;152:1819-26.

37. Surette MG, Bassler BL. Quorum sensing in Escherichia coli and Salmonella typhimurium. Proc Natl Acad Sci U S A 1998;95(12):7046-50.

38. Xu L, Li H, Vuong C, Vadyvaloo V, Wang J, Yao Y, et al. Role of the luxS quorum-sensing system in biofilm formation and virulence of 
Staphylococcus epidermidis. Infect Immun 2006;74(1):488-96.

39. Winson MK, Swift S, Fish L, Throup JP, Jørgensen F, Chhabra SR, et al. Construction and analysis of luxCDABE-based plasmid sensors for investigating $\mathrm{N}$-acyl homoserine lactone-mediated quorum sensing. FEMS Microbiol Lett 1998;163(2):185-92.

40. Janssens JC, Steenackers H, Robijns S, Gellens E, Levin J, Zhao $\mathrm{H}$, et al. Brominated furanones inhibit biofilm formation by Salmonella enterica serovar Typhimurium. Appl Environ Microbiol 2008;74(21):6639-48

41. Kagan S, Jabbour A, Sionov E, Alquntar AA, Steinberg D, Srebnik M, et al. Anti-Candida albicans biofilm effect of novel heterocyclic compounds. J Antimicrob Chemother 2013;69:416-27.

42. Jonnalagadda S, Deshabathini UK. Anti quorum sensing potential of Moringa oleifera seed extract. Int J Pharm Pharm Sci 2016;8(1):76-82.

43. Mutungwa W, Alluri N, Majumdar M. Anti-quorum sensing activity of some commonly used traditional Indian spices. Int J Pharm Pharm Sci 2015;7(11):80-3

44. Mary RN, Banu N. Screening of antibiofilm and anti-quorum sensing potential of Vitex trifolia in Pseudomonas aeruginosa. Int J Pharm Pharm Sci 2015;7(8):242-5. 